\title{
Austrian Committee for Injury Prevention in Childhood
}

\author{
Katharina Purtscher, Johannes Mayr
}

The Austrian Committee for Injury Prevention in Childhood (ÖKU) is a non-profit organisation with the goal of reducing childhood injuries, especially severe and disabling injuries, and child deaths. Dr Hugo Sauer, at that time head of the Department of Paediatric Surgery in Graz, other paediatric surgeons, paediatricians, and people from other professional backgrounds founded the committee in 1983. Dr Sauer served as president till 1992. Since 1993 Dr Michael Höllwarth has been the committee's second president.

The committee also has an advisory council, whose members reflect a wide range of different professional backgrounds. The advisory council provides assistance in implementing local injury prevention activities.

\section{Aims and goals}

To reduce the number and severity of childhood injuries was and is the goal of the committee. From the start special emphasis was given to the prevention of severe and disabling injuries.

At the very beginning agricultural injuries, in particular, in children was an area of major concern. An information campaign on preventive measures of severe agricultural injuries was carried out in close cooperation with the Farmers' Social Security Institution.

The committee addresses major injury risks to children. The following risk areas have been identified as priorities: bicycle injuries, passenger safety, safety at home, and playground injuries.

The main focus of research is collecting injury event data, especially on playground injuries, baby walker related injuries, and psychosocial risk factors of childhood injuries. All kinds of sports injuries, household injuries, and evaluation of the prevention strategies are also studied. In these studies certain types of injuries, the contributing risk factors, and their outcome and sequelae are examined regularly, due to the clinical work of the committee's members.

for Injury Prevention in Childhood, Auenbruggerplatz 34, Graz 8036, Austria K Purtscher

J Mayr

Correspondence to: Dr Purtscher.

\section{Information distribution}

Information on common risk areas and risk behaviour in agriculture and in the home environment is regularly spread by brochures and pamphlets. Parents, teachers, and carers in kindergartens and schools are addressed through several age appropriate information materials.

\section{Major prevention programmes \\ HELMET CAMPAIGN}

In 1991 a local bicycle helmet campaign was launched in cooperation with school traffic safety education authorities. After being successfully implemented in the county of Styria this programme was adopted by the Austrian Ministry of Education and was launched statewide in 1994. Funding of the programme comes from traffic safety funds of each county and the state. Statewide enforcement campaigns helped to raise the helmet usage rate all over Austria. The evaluation of this helmet campaign showed an increase in helmet usage of children from $8 \%$ to $36 \%$ in 1996 in the intervention area.

CAR SAFETY SEAT LOAN PROGRAMME

Car safety seats for children have been mandatory since 1996, and since 1992 every delivery department in the federal province of Styria has established a child safety seat loan programme for newborn babies. Because of the easy accessibility of car safety seats higher usage rates $(87 \%)$ were shown than in a comparison area without a loan programme $(60 \%)$. A statewide enforcement campaign helped to raise awareness and increase usage rates of car safety seats as shown in the evaluation.

HOME SAFETY PROGRAMME

To prevent the most frequent household injuries like poisoning, scalds and burns, a home safety box was developed. The aim of the committee is to offer parents inexpensive and easy access to home safety devices. This box contains 11 most useful safety devices-like lockers, window guards, a stove guard, a smoke detector, and safety plugs for sockets-to prevent home injuries. Subsidized by the local government housing department, the safety box is available for families with children aged 6 years and under for free.

After a series of playground equipment related injuries in children in 1993 we conducted a retrospective investigation of the mode of acci- 
dent, type of playground equipment involved, and type of injury in 374 playground accidents. Thirty one per cent of children injured in playground accidents sustained fractures of the extremities or concussion of the brain. Swings, slides, climbing frames, metal bars, and merrygo-rounds accounted for $71 \%$ of the playground equipment related accidents. Falls were responsible for most of these accidents $(71 \%)$ and in one third of falls the ground at the impact site consisted of bare earth, concrete, asphalt, or stones. We sent questionnaires to the parents of these children and obtained more detailed information on 103 playground accidents. ${ }^{1}$ Together with the Austrian Standards Institute and TÜV-Austria we investigated parameters correlating with injury severity scores in falls related to playground equipment and measured peak $\mathrm{g}$ ( $\mathrm{g}$ force $=$ accelerative force) and HIC (head injury criterion) values at authentic accident sites. ${ }^{2}$ We found a correlation between the product of height of fall (metres) $\times$ age of child (years) with injury severity score. ${ }^{3}$ We strongly recommend that the maximum height of playground equipment is limited to 1.6 meters and that some kind of impact absorbing surface is used in playgrounds where falls might occur.

Experts on the committee took part in the preparation of revised European playground standards. We held numerous seminars and lectures on playground safety all over Austria and presented our strategies for improvement of playground safety repeatedly in the media. We created a playground safety folder and for playground owners all over Styria we offer a playground safety check; this includes the main safety inspection of the playground once or twice a year by our institution. Since we launched our playground safety programme in 1997 we have checked more than 120 public Styrian playgrounds on request.

\section{Car safety in public transport}

The programme "Safe Taxis for Children" aims to propagate the use of car safety seats for children in taxis as currently they are not compulsory for taxis in Austria. As a first step taxi drivers are taught about the wider field of traffic safety and in the correct mounting of car safety seats. Secondly people are informed about the campaign by newspapers and television. Since October 1997 the safe transport of children in taxis has been offered by one large taxi company.

\section{School safety}

The school safety programme was initiated by the committee in 1993 and ran in 14 Styrian schools for nearly two years. The school safety programme is a model of good practice and how to create school safety teams in which pupils of all age groups (9-18) can participate. Partners in this programme are the Austrian Workers' Compensation Board and the Austrian Ministry of Education. The school safety programme is supposed to cover two fields: injury prevention and health promotion for young people. Both fields should be seen as an integral part of school education.

\section{Education and training}

The committee regularly provides training for teachers and carers in kindergartens and day care centres. Since 1995 the committee has developed a special curriculum to educate and train local field experts. Paediatricians, family doctors, nurses, teachers and caregivers, as well as health care professionals, are attending this education programme.

\section{Funding}

As a non-governmental organisation the committee has always relied on grant money for its activities. The main support has come from the county government, particularly the local health department. Hospital personnel like doctors are contributing to injury prevention research and programme development.

Private sponsorship has always been a resource but until recently the amount of money was small. Since 1998 the committee has worked in close cooperation with Johnson \& Johnson - an international company already involved in childhood injury prevention as funding sponsor of the National SAFE KIDS Campaign (USA). This sponsorship was agreed upon for the next five years.

\section{Conclusion}

To develop an injury prevention programme, bring the prevention strategies in place, and evaluate the outcome of the intervention is how we address injury risks of recognised priority. To spread our successful programme nationwide we jointly collaborate with several organisations, public agencies, and individuals.

1 Mayr J, Russe O, Spitzer P, et al. Playground accidents. Acta Paediatr 1995;84:573-6.

2 Chou CC, Nyquist GW. Analytical study of the head injury criterion (HIC). New York: Society of Automotive Engineers, 1974. (Report No 740082.)

3 Mayr J, Fiala F, Guschelbauer E. Parameters correlating to injury severity score in playground-related fall accidents. International fournal of Consumer Safety 1996;3:147-52. 